\title{
Dual Emission Fluorescent Silver Nanoclusters for Sensitive Detection of the Biological Coenzyme NAD ${ }^{+} /$NADH
}

Yufeng Yuan, ${ }^{\mathrm{a}}$ Kehan Huang, ${ }^{\mathrm{a}}$ Mengfang Chang, ${ }^{\mathrm{a}}$ Cuifang Qin, ${ }^{\mathrm{a}}$ Sanjun Zhang, ${ }^{\mathrm{a}}$ Haifeng Pan, ${ }^{\mathrm{a}, *}$ Yan Chen, ${ }^{\mathrm{b}}$ Jianhua $\mathrm{Xu}{ }^{\mathrm{a}}$

${ }^{\mathrm{a}}$ State Key Laboratory of Precision Spectroscopy, East China Normal University, Shanghai, 200062, China

${ }^{\mathrm{b}}$ TongjiHospital Affiliated to Tongji University, Shanghai, 200065, China

\begin{abstract}
Fluorescent silver nanoclusters (Ag NCs) displaying dual-excitation and dual-emission properties have been developed for the specific detection of NAD ${ }^{+}$. With the increase of $\mathrm{NAD}^{+}$concentrations, the longer wavelength emission (with the peak at $550 \mathrm{~nm}$ ) was gradually quenched due to the strong interactions between the $\mathrm{NAD}^{+}$and $\mathrm{Ag} \mathrm{NCs}$, while the shorter wavelength emission (peaking at $395 \mathrm{~nm}$ ) was linearly enhanced. More importantly, the dual-emission intensity ratio $\left(\mathbf{I}_{\mathbf{3 9 5}} / \mathbf{I}_{\mathbf{5 5 0}}\right)$, fitting by a single-exponential decay function, can efficiently detect various $\mathrm{NAD}^{+}$ levels from $100 \mu \mathrm{M}$ to $4000 \mu \mathrm{M}$, as well as label $\mathrm{NAD}^{+} / \mathrm{NADH}$ ratios in the range of 1 to 50 .
\end{abstract}

Keywords: Dual-emission fluorescent silver nanoclusters, Dual-emission intensity ratio, Biological coenzyme $\mathrm{NAD}^{+}, \mathrm{NAD}^{+} / \mathrm{NADH}$ ratios

\section{Introduction}

The biological coenzyme $\mathrm{NAD}^{+}$, and its reduced form $\mathrm{NADH}$, are critical intermediates of cellular energy metabolism, mitochondrial function, gene expression, calcium homeostasis, cell death, aging, and carcinogenesis. [1-7] In light of the important roles that $\mathrm{NAD}^{+}$and $\mathrm{NADH}$ play in redox processes, it is of considerable significance to develop sensitive and specific sensors for monitoring $\mathrm{NAD}^{+} / \mathrm{NADH}$.

Thus far, various efficient and reproducible biochemical methods, such as high 
performance liquid chromatography (HPLC), [8] capillary electrochromatography (CE), [9] and enzymatic cycling assay, [2] have been developed to detect NAD ${ }^{+}$levels. However, these methods have the drawbacks of high cost, time-consumption, and destructive sample processing. Unlike other polycyclic aromatic coenzymes with strong fluorescence (such as NADH, NADPH, and FAD), $\mathrm{NAD}^{+}$has no fluorescent chromophore.[10] Therefore, it is impossible to directly detect $\mathrm{NAD}^{+}$via fluorescence measurement. Many investigators have created genetically encoded fluorescent protein biosensors (Rex, cpFPs, Peredox, Frex/Frexh) to report NAD ${ }^{+}$levels.[2-3, 6, 11-13] It is interesting to note that the protein sensors demonstrate stronger affinity to $\mathrm{NADH}$ than $\mathrm{NAD}^{+}$. In fact, genetically encoded fluorescent proteins are not specific sensors for $\mathrm{NAD}^{+}$. Moreover, in living cells, the level of $\mathrm{NAD}^{+}$dominates in the total levels of $\mathrm{NAD}^{+} / \mathrm{NADH}$. Therefore, a specific and sensitive $\mathrm{NAD}^{+}$sensor would be more preferred and valuable. Although these protein biosensors open up new avenues in developments of high performance sensors for the sensitive detection of $\mathrm{NAD}^{+} / \mathrm{NADH}$, there is still a great need for the development of fluorescent nano-sensors with not only high sensitivity and selectivity but also low operation cost. Until now, there are few reports about sensitive sensors that directly detect the biological molecule $\mathrm{NAD}^{+}$.

Recently, silver nanoclusters (Ag NCs) have attracted considerable attention because of their excellent photo-stability, non-toxicity, low steric hindrance properties, and tunable fluorescence emissions. In contrast to the large size of Ag nanoparticles (Ag NPs), the Ag NCs can be synthesized in many stabilizing scaffolds, such as dendrimers,[14] polymers,[15-16] proteins,[17] and DNA.[18] Among those templates, DNA, oligonucleotide, and nucleobases-templated Ag NCs have received special attention, because some nucleobases are excellent ligands for the $\mathrm{Ag}$ NCs.[18-20] Since $\mathrm{NAD}^{+}$contains active nitrogen atoms and $\pi$ electron systems (adenine, nicotinamide moieties), it has been proved that they can strongly interact with the metal nanoparticles. Here we reported a sensitive probe of $\mathrm{NAD}^{+}$, named dual-emission fluorescent $\mathrm{Ag} \mathrm{NCs,} \mathrm{which} \mathrm{can} \mathrm{be} \mathrm{used} \mathrm{to} \mathrm{monitor} \mathrm{NAD}^{+}$levels and various $\mathrm{NAD}^{+} / \mathrm{NADH}$ ratios, and to facilitate practical biological coenzyme detection. 


\section{Materials and methods}

\section{Materials}

All the reagents were used without any further purification. Nicotinamide adenine dinucleotide disodium salts $\left(\mathrm{NAD}^{+}(98 \%)\right.$, and its reduced form, NADH (98\%)) were purchased from Roche Company. Silver nitrate $\left(\mathrm{AgNO}_{3}\right)$, and ascorbic acid were bought from Sinopharm Chemical Reagent Co., Ltd (Shanghai, China). Cysteamine (96\%) was bought from J\&K Chemical Ltd (Shanghai, China). Ultrapure water (18.2 $\mathrm{M} \Omega$ ) was used throughout all the experiments.

Synthesis of Ag NCs

The Ag NCs were prepared in two steps: the modification of Ag NPs with cysteamine, and the second etching of NAD ${ }^{+}$. The Ag NPs were fabricated as follows: at room temperature, $5 \mathrm{~mL}$ distilled water and freshly prepared ascorbic acid $(75 \mu \mathrm{L}$, $10 \mathrm{mM}$ ) were injected in a clean beaker under vigorous stirring. Silver nitrate solution ( $3 \mathrm{~mL}, 0.5 \mathrm{mM}$ ) was added into the reaction mixture solution drop by drop. 5 minutes later, the Ag NPs were completed. The prepared Ag NPs $(900 \mu \mathrm{L})$ were modified by cysteamine solution $(100 \mu \mathrm{L}, 50 \mu \mathrm{M})$ with a molar ratio of (1:8). 3 hours later, the cysteamine capped $\mathrm{Ag}$ NCs formed. In order to allow for efficient interactions, $\mathrm{NAD}^{+}$ with different concentrations and cysteamine capped Ag NCs were mixed and equilibrated 3 hours before spectral measurements.

Instrumental measurements

At room temperature, the steady fluorescence spectra were measured by a Hitachi F-4500 spectrofluorometer with $5 \mathrm{~nm}$ slits, PMT voltage at $700 \mathrm{~V}$, and $240 \mathrm{~nm} / \mathrm{min}$ scanning speed.

\section{Results and discussion}

The procedure for $\mathrm{NAD}^{+}$detection via dual-emission fluorescent $\mathrm{Ag} \mathrm{NCs}$

The procedure for the detection of $\mathrm{NAD}^{+}$via fluorescent $\mathrm{Ag} \mathrm{NCs}$ is shown in Scheme 1. The Ag NCs were prepared and synthesized by two etching processes. After the first modification of the small thiol molecule cysteamine, the initial fluorescence emission peak of cysteamine capped Ag NCs locates around $550 \mathrm{~nm}$ 
(Fig.1). Due to the positive charge on the surface of Ag NCs, it has a high affinity to negative $\mathrm{NAD}^{+}$ligands, which are good electron donors. The interactions between the $\mathrm{Ag} \mathrm{NCs}$ and the $\mathrm{NAD}^{+}$ligands caused an obvious change in the fluorescence emission spectrum. The levels of $\mathrm{NAD}^{+}$can be calculated by measuring the dual-emission of Ag NCs.

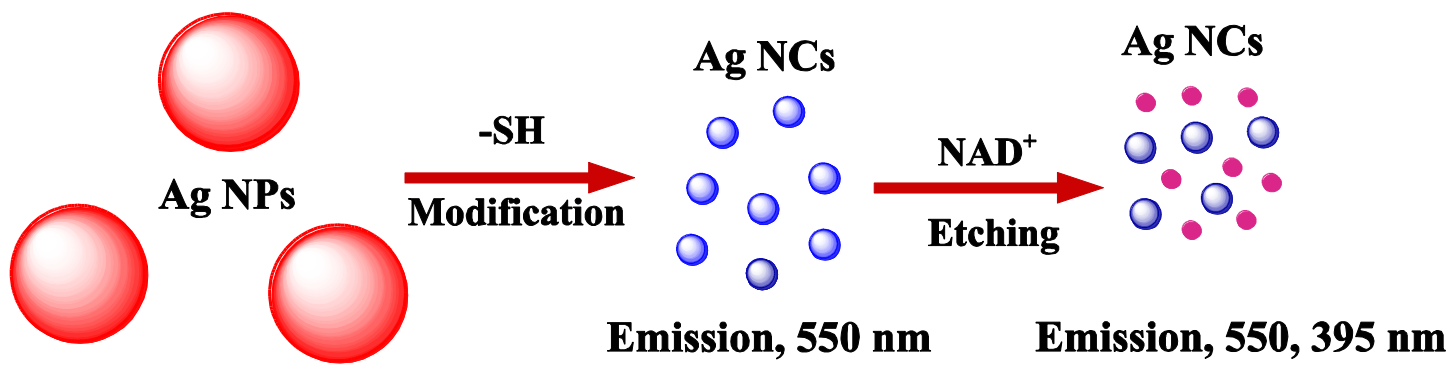

Scheme 1 Schematic representation of the procedure for the detection of $\mathrm{NAD}^{+}$via dual-emission Ag NCs

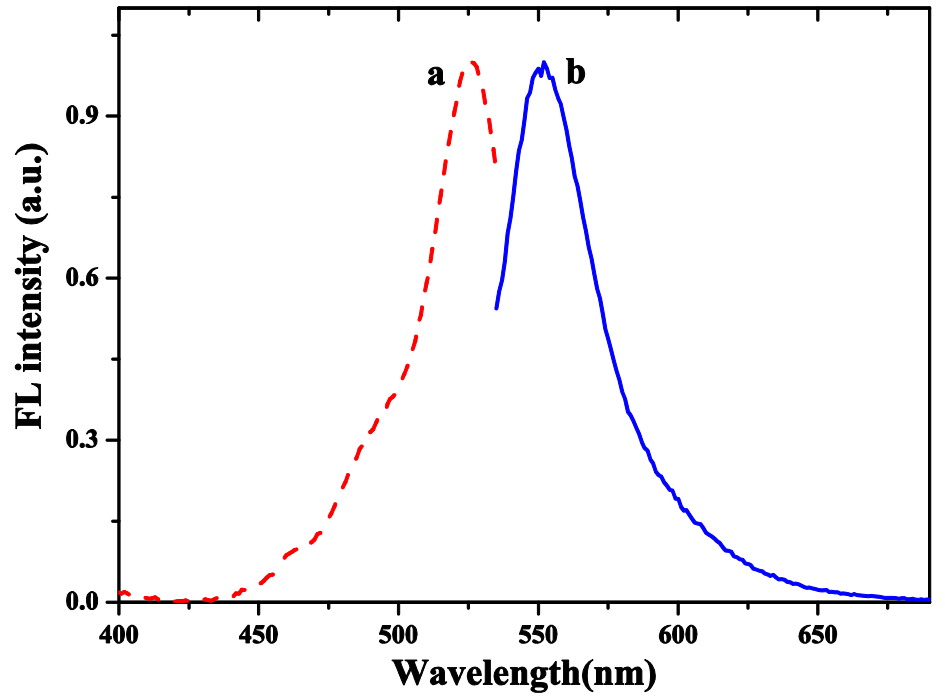

Fig.1 The normalized steady state excitation (dash red curve) and emission (solid blue curve) spectra of cysteamine capped Ag NCs

Sensitive detection of $\mathrm{NAD}^{+}$via dual-emission fluorescent Ag NCs

Figure 2 shows the relation of dual-emission $(550 \mathrm{~nm}, 395 \mathrm{~nm})$ fluorescence intensity with $\mathrm{NAD}^{+}$concentrations. There are strong interactions between $\mathrm{Ag} \mathrm{NCs}$ and $\mathrm{NAD}^{+}$molecules, which caused the quenching of the longer wavelength emission (550 nm, Fig.2(A)), and produced a new and enhanced short wavelength emission (395 nm, Fig.2(C)). The fluorescence intensity at longer wavelength was quenched 
quickly when the $\mathrm{NAD}^{+}$concentration was in the range of $0.1-500 \mu \mathrm{M}$ (Fig.2(B)). There is no significant appearance of new fluorescence emissions with $\mathrm{NAD}^{+}$ concentrations lower than $100 \mu \mathrm{M}$. However, a new fluorescence peak at $395 \mathrm{~nm}$ increases linearly with $\mathrm{NAD}^{+}$concentrations from $100 \mu \mathrm{M}$ to $4 \mathrm{mM}$ (Fig.2(C) \&Fig.2(D)). Since $\mathrm{NAD}^{+}$acts as an etching ligand to cysteamine capped Ag NCs, another type of Ag NCs was formed, which has a fluorescence emission at $395 \mathrm{~nm}$.
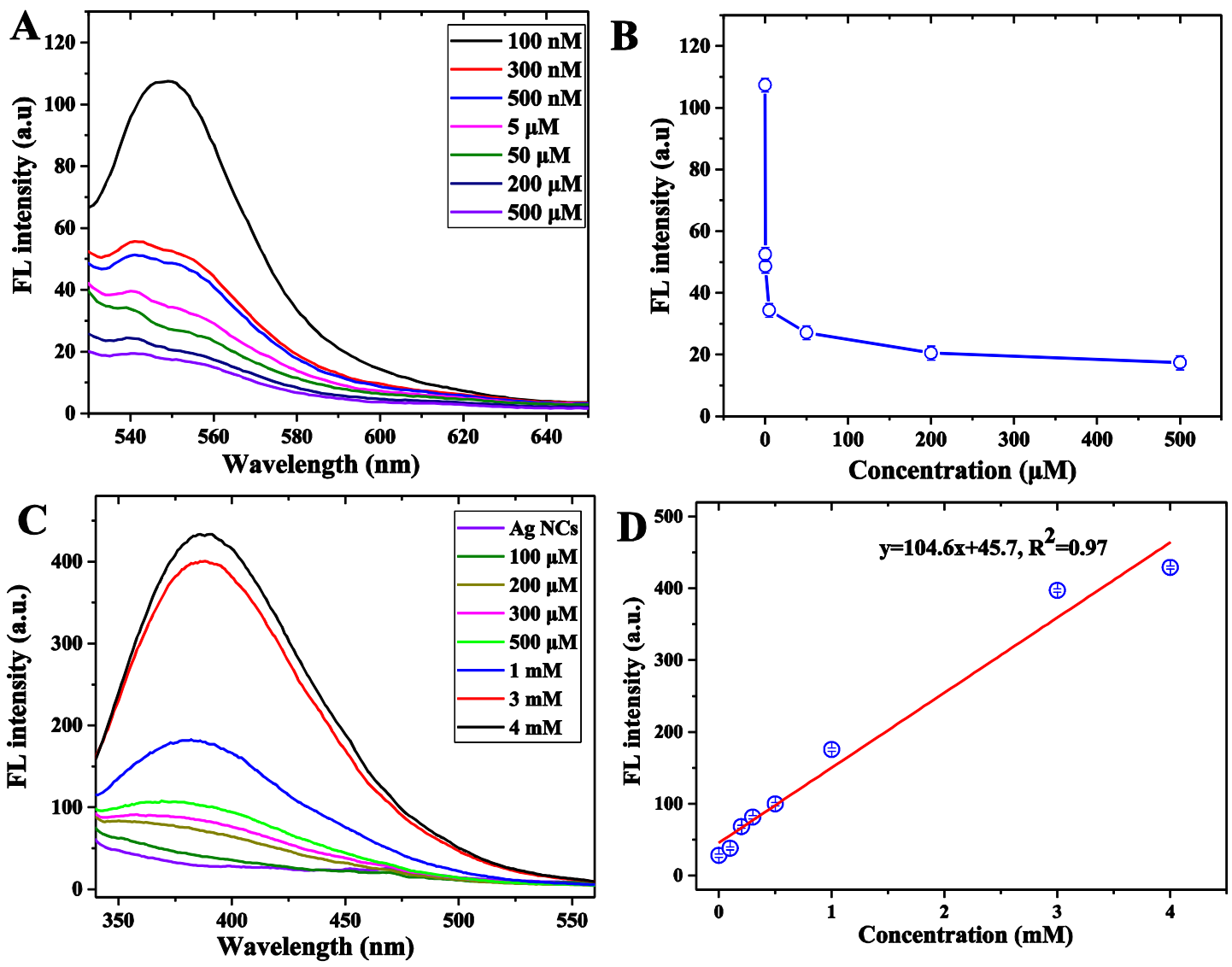

Fig.2 The relation of dual-emission steady state fluorescence intensity with $\mathrm{NAD}^{+}$concentrations. (EM 550 nm, Fig.2(A)\&Fig.2(B), EX 510 nm; EM 395 nm,Fig.2(C)\&Fig.2(D), EX 290 nm)

The fluorescence emissions at 395 and $550 \mathrm{~nm}$ showed different dependences on the $\mathrm{NAD}^{+}$concentration. The fluorescence intensity ratio $\left(\mathbf{I}_{\mathbf{3 9 5}} / \mathbf{I}_{\mathbf{5 5 0}}\right)$ curve can be described by an exponential function of $\mathrm{NAD}^{+}$concentrations, as shown in Fig.3. The curve of the fluorescence intensity ratio $\left(\mathbf{I}_{\mathbf{3 9 5}} / \mathbf{I}_{\mathbf{5 5 0}}\right)$ against various $\mathrm{NAD}^{+}$ concentrations shows a good mono-exponential dependence from $100 \mu \mathrm{M}$ to $4000 \mu \mathrm{M}$. Actually, exponential decay function models have already been used to explain the fluorescence intensity quenching of some metal nanoparticles, due to the interactions 
between analytes and nanoparticles with binding constant.[21-22] Reported actual concentrations of $\mathrm{NAD}^{+}$are $\sim 300 \mathrm{mM}$ in animal cells $[8,23]$ and $\sim 1 \mathrm{mM}$ in yeast.[24] Therefore, the efficient detection limit of dual-emission Ag NCs can satisfy the requirements of $\mathrm{NAD}^{+}$detection in living cells and cell extracts. In addition, compared with single fluorescence emission detection, the dual-emission Ag NCs can avoid some experimental errors from current measurement systems and enhance the precision of detection methods. The equation of fit (Fig.3) shows that the detection precision can be elevated by a factor of almost 18. Therefore, the dual-emission intensity ratio can efficiently label the $\mathrm{NAD}^{+}$concentrations.

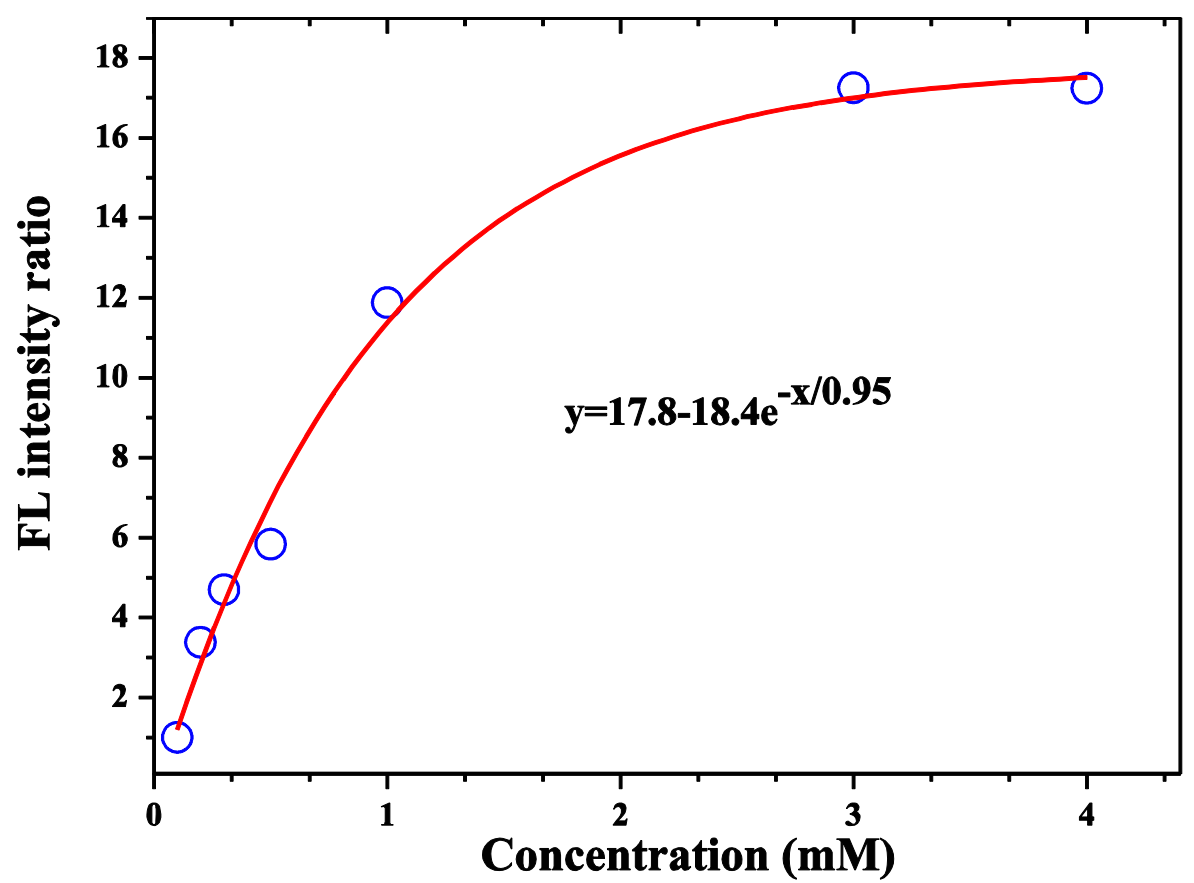

Fig.3 The responses of the fluorescence intensity ratio $\left(\mathbf{I}_{395} / \mathbf{I}_{\mathbf{5 5 0}}\right)$ against various $\mathrm{NAD}^{+}$ concentrations from $100 \mu \mathrm{M}$ to $4000 \mu \mathrm{M}$.

Specificity detection of $\mathrm{NAD}^{+}$via dual-emission fluorescent $\mathrm{Ag} \mathrm{NCs}$

Besides the sensitivity of the fluorescent $\mathrm{Ag} \mathrm{NC}$ sensor, high specificity is also important in real sample detections. To evaluate the specificity of fluorescent Ag NCs, we selected $\mathrm{NADH}$ as the coordinating ligand to measure the fluorescence changes of Ag NCs under the same conditions. However, there is no significant fluorescence emission located at $395 \mathrm{~nm}$ (Fig.4).The difference between $\mathrm{NAD}^{+}$and NADH is that NADH has reduced nicotinamide moiety, causing the poor electron-transfer capacity 
between $\mathrm{Ag} \mathrm{NCs}$ and the coordinating ligands, which cannot support the luminescence of $\mathrm{Ag}$ NCs. Thus, the fluorescent $\mathrm{Ag}$ NC sensor shows a good selectivity for $\mathrm{NAD}^{+}$. Although the fluorescent $\mathrm{Ag} \mathrm{NCs}$ are not sensitive to the presence of $\mathrm{NADH}$, it provides the possibility to label $\mathrm{NAD}^{+} / \mathrm{NADH}$ ratios.

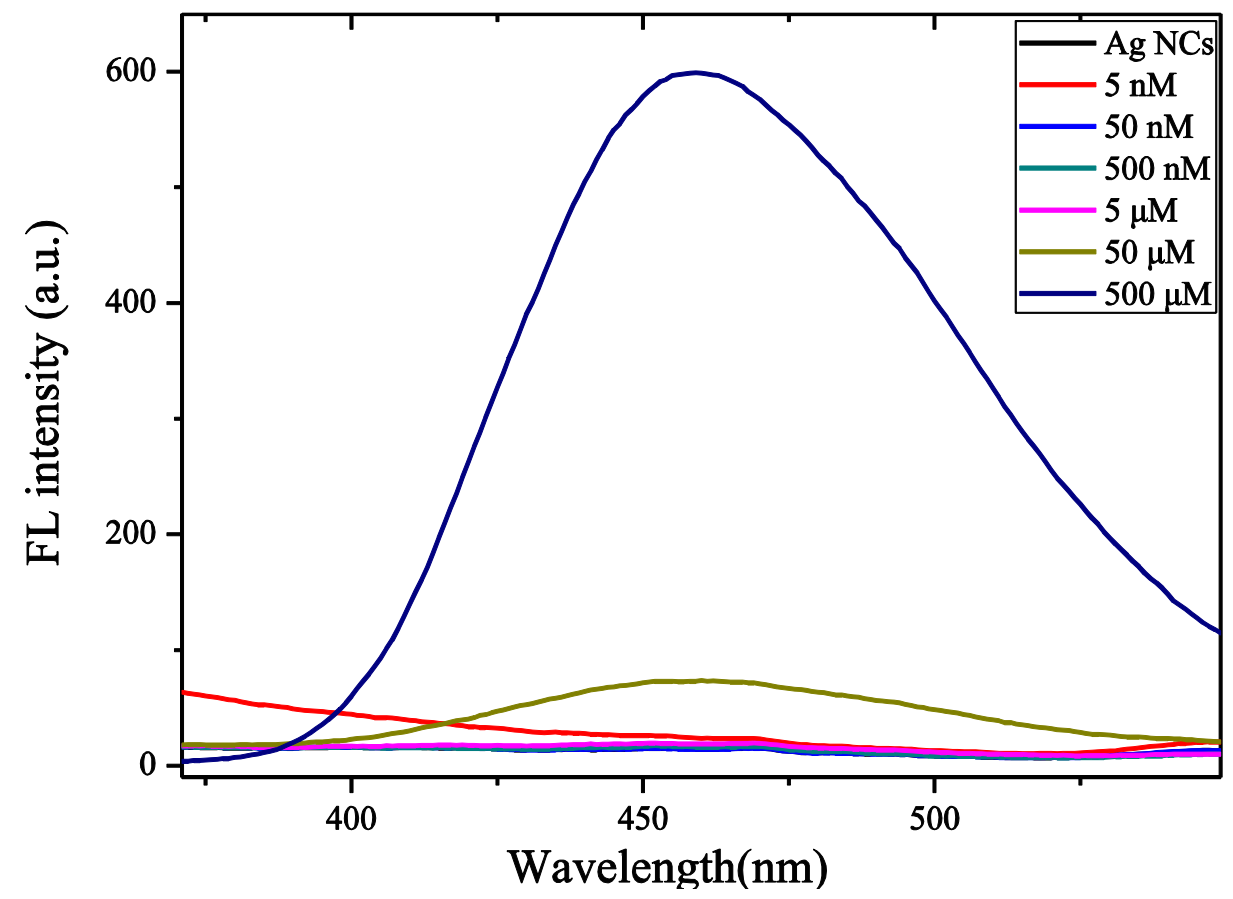

Fig.4 The steady state fluorescence spectra of Ag NCs $v s$ various NADH concentrations. The excitation wavelength is $295 \mathrm{~nm}$.

The feasibility of $\mathrm{NAD}^{+} / \mathrm{NADH}$ ratio detection via dual-emission fluorescent Ag NCs

The $\mathrm{NAD}^{+} / \mathrm{NADH}$ ratio plays a crucial role in regulating the redox state, which is an important indicator of metabolic state. For many years, investigators have estimated the ratios of $\mathrm{NAD}^{+} / \mathrm{NADH}$ as follows: 3 in yeast, 4-10 in Escherichia coli, 3-10 in mammals, 7-8 in mitochondria, and 700-1 in cytosol.[3, 25-28] In this paper, we further studied whether $\mathrm{Ag} \mathrm{NCs}$ can be used to label $\mathrm{NAD}^{+} / \mathrm{NADH}$ ratios when the total concentration of $\mathrm{NAD}^{+}$and $\mathrm{NADH}$ is approximately $500 \mu \mathrm{M}$. Fig.5 shows the response of the dual-emission intensity ratio $\left(\mathbf{I}_{395} / \mathbf{I}_{550}\right)$ versus NAD ${ }^{+} / \mathrm{NADH}$ ratios. The dual-emission intensity ratio curve is modeled by a single-exponential decay function with $\mathrm{NAD}^{+} / \mathrm{NADH}$ ratios ranging from 1 to 300 . However, the efficient detection range is $1-50$. There is a competitive interaction mechanism between $\mathrm{NAD}^{+}$ 
and NADH. NAD ${ }^{+}$competes with $\mathrm{NADH}$ in interacting with $\mathrm{Ag} \mathrm{NCs}$, and increasing the $\mathrm{NAD}^{+} / \mathrm{NADH}$ ratio efficiently strengthens the interactions between $\mathrm{NAD}^{+}$and $\mathrm{Ag}$ $\mathrm{NCs}$. When $\mathrm{NAD}^{+} / \mathrm{NADH}$ ratios range from 1 to 50 , the corresponding dual-emission intensity ratios increase significantly. However, when $\mathrm{NAD}^{+} / \mathrm{NADH}$ ratios exceed 50, the dual-emission intensity ratios tend to become stable, because $\mathrm{NAD}^{+}$completely dominated in the competition with NADH. Therefore, the Ag NCs can also probe $\mathrm{NAD}^{+} / \mathrm{NADH}$ ratios from 1 to 50 .

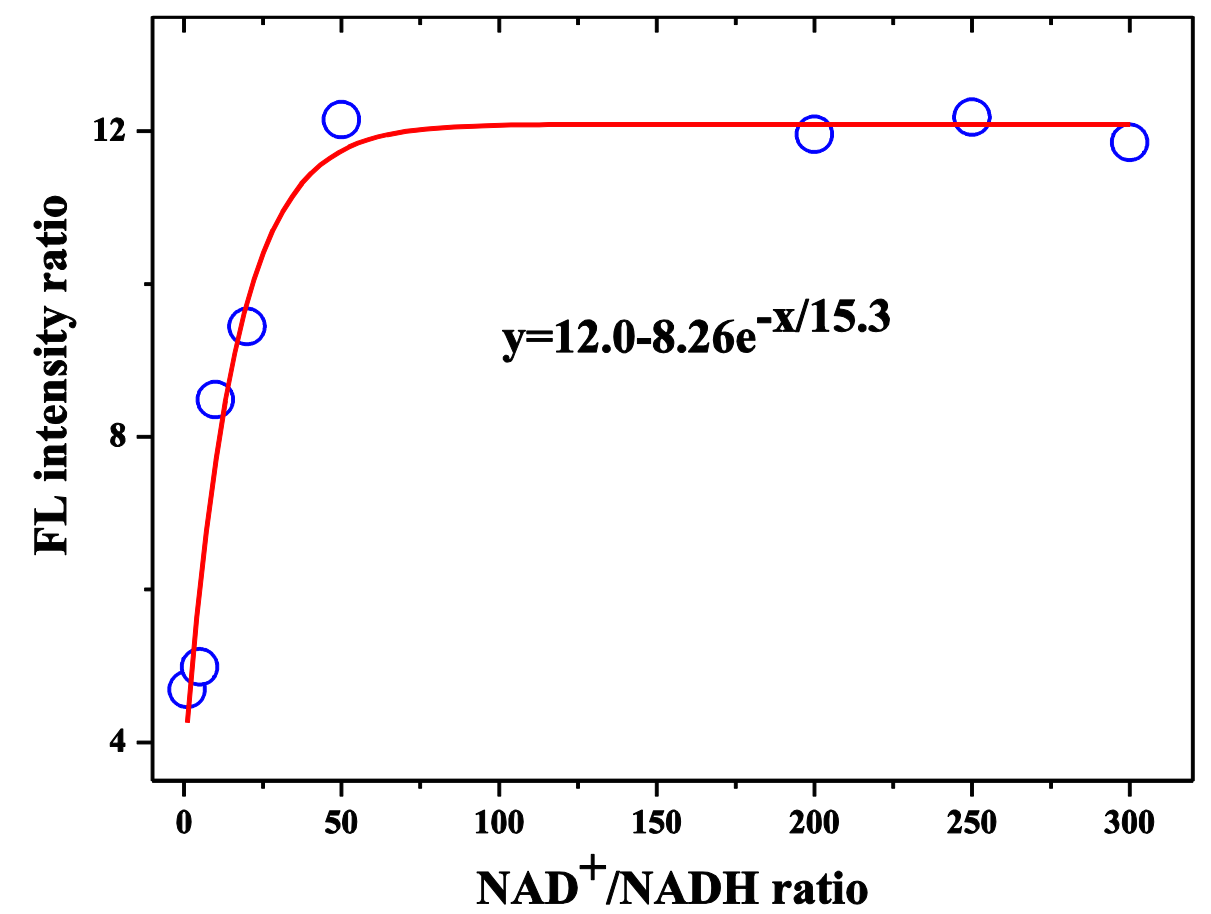

Fig. 5 The responses of the fluorescence intensity ratio $\left(\mathbf{I}_{395} / \mathbf{I}_{\mathbf{5 0 0}}\right)$ versus various $\mathrm{NAD}^{+} / \mathrm{NADH}$ ratios from 1 to 300 . The total concentration of $\mathrm{NAD}^{+}$and $\mathrm{NADH}$ is about $500 \mu \mathrm{M}$

\section{Conclusions}

In the paper, we have designed and created novel dual-emission fluorescence $\mathrm{Ag}$ $\mathrm{NCs}$, which are ideal for the sensitive detection of $\mathrm{NAD}^{+}$and $\mathrm{NAD}^{+} / \mathrm{NADH}$ ratios. The dual-emission intensity ratio can eliminate the experimental error from detection methods. More importantly, the fitted single-exponential decay curves of the fluorescence emission intensity ratio $\left(\mathbf{I}_{\mathbf{3 9 5}} / \mathbf{I}_{\mathbf{5 5 0}}\right)$ can efficiently label the $\mathrm{NAD}^{+}$ concentrations and $\mathrm{NAD}^{+} / \mathrm{NADH}$ ratios from 1 to 50 .

\section{Author information}

\section{Corresponding Author}


E-mail: hfpan@phy.ecnu.edu.cn

\section{Acknowledgments}

This work was partly supported by the National Science Foundation of China (61178085, 61108077), the Science and Technology Commission of Shanghai Municipality (15ZR1411700), and the Program of Introducing Talents of Discipline to Universities (B12024)

\section{References}

[1] K. Eto, Y. Tsubamoto, Y. Terauchi, T. Sugiyama, T. Kishimoto, N. Takahashi, N. Yamauchi, N. Kubota, S. Murayama, S. Aizawa, Y. Akanuma, S. Aizawa, H. Kasai, Y. Yazaki, T. Kadowaki, Role of NADH shuttle system in glucose-induced activation of mitochondrial metabolism and insulin secretion, Science, 283 (1999) 981-985.

[2] Q.H. Zhang, S.Y. Wang, A.C. Nottke, J.V. Rocheleau, D.W. Piston, R.H. Goodman, Redox sensor CtBP mediates hypoxia-induced tumor cell migration, P Natl Acad Sci USA, 103 (2006) 9029-9033.

[3] Q.H. Zhang, D.W. Piston, R.H. Goodman, Regulation of corepressor function by nuclear NADH, Science, 295 (2002) 1895-1897.

[4] K.A. Kasischke, H.D. Vishwasrao, P.J. Fisher, W.R. Zipfel, W.W. Webb, Neural activity triggers neuronal oxidative metabolism followed by astrocytic glycolysis, Science, 305 (2004) 99-103.

[5] S.J. Lin, L. Guarente, Nicotinamide adenine dinucleotide, a metabolic regulator of transcription, longevity and disease, Curr Opin Cell Biol, 15 (2003) 241-246.

[6] J. Rutter, M. Reick, L.C. Wu, S.L. McKnight, Regulation of Clock and NPAS2 DNA Binding by the Redox State of NAD Cofactors, Science, 293 (2001) 510-514.

[7] G.N. Vemuri, M.A. Eiteman, J.E. McEwen, L. Olsson, J. Nielsen, Increasing NADH oxidation reduces overflow metabolism in Saccharomyces cerevisiae, P Natl Acad Sci USA, 104 (2007) 2402-2407.

[8] H.Y. Yang, T. Yang, J.A. Baur, E. Perez, T. Matsui, J.J. Carmona, D.W. Lamming, N.C. Souza-Pinto, V.A. Bohr, A. Rosenzweig, R. de Cabo, A.A. Sauve, D.A. Sinclair, Nutrient-sensitive mitochondrial NAD(+) levels dictate cell survival, Cell, 130 (2007) 1095-1107.

[9] W.J. Xie, A.S. Xu, E.S. Yeung, Determination of NAD(+) and NADH in a Single Cell under Hydrogen Peroxide Stress by Capillary Electrophoresis, Anal Chem, 81 (2009) 1280-1284.

[10] B. Chance, B. Schoener, R. Oshino, F. Itshak, Y. Nakase, Oxidation-reduction ratio studies of mitochondria in freeze-trapped samples. NADH and flavoprotein fluorescence signals, J Biol Chem, 254 (1979) 4764-4771.

[11] J. Berg, Y.P. Hung, G. Yellen, A genetically encoded fluorescent reporter of ATP:ADP ratio, Nat Methods, 6 (2009) 161-166.

[12] Y.P. Hung, J.G. Albeck, M. Tantama, G. Yellen, Imaging Cytosolic NADH-NAD(+) Redox State with a Genetically Encoded Fluorescent Biosensor, Cell Metab, 14 (2011) 545-554.

[13] Y.Z. Zhao, J. Jin, Q.X. Hu, H.M. Zhou, J. Yi, Z.H. Yu, L. Xu, X. Wang, Y. Yang, J. Loscalzo, Genetically 
Encoded Fluorescent Sensors for Intracellular NADH Detection, Cell Metab, 14 (2011) 555-566.

[14] J. Zheng, R.M. Dickson, Individual water-soluble dendrimer-encapsulated silver nanodot fluorescence, J Am Chem Soc, 124 (2002) 13982-13983.

[15] J.G. Zhang, S.Q. Xu, E. Kumacheva, Photogeneration of fluorescent silver nanoclusters in polymer microgels, Adv Mater, 17 (2005) 2336-+.

[16] Z. Shen, H.W. Duan, H. Frey, Water-soluble fluorescent Ag nanoclusters obtained from multiarm star poly(acrylic acid) as "molecular hydrogel" templates, Adv Mater, 19 (2007) 349-+.

[17] S.S. Narayanan, S.K. Pal, Structural and functional characterization of luminescent silver-protein nanobioconjugates, J Phys Chem C, 112 (2008) 4874-4879.

[18] J.T. Petty, J. Zheng, N.V. Hud, R.M. Dickson, DNA-templated Ag nanocluster formation, Journal of the American Chemical Society, 126 (2004) 5207-5212.

[19] C.I. Richards, S. Choi, J.C. Hsiang, Y. Antoku, T. Vosch, A. Bongiorno, Y.L. Tzeng, R.M. Dickson, Oligonucleotide-stabilized Ag nanocluster fluorophores, Journal of the American Chemical Society, 130 (2008) 5038-+.

[20] K.V. Mrudula, T.U.B. Rao, T. Pradeep, Interfacial synthesis of luminescent 7 kDa silver clusters, J Mater Chem, 19 (2009) 4335-4342.

[21] X.H. Huang, I.H. El-Sayed, X.B. Yi, M.A. El-Sayed, Gold nanoparticles: Catalyst for the oxidation of NADH to NAD(+), J Photoch Photobio B, 81 (2005) 76-83.

[22] J. Zhang, R. Badugu, J.R. Lakowicz, Fluorescence quenching of CdTe nanocrystals by bound gold nanoparticles in aqueous solution, Plasmonics, 3 (2008) 3-11.

[23] K. Yamada, N. Hara, T. Shibata, H. Osago, M. Tsuchiya, The simultaneous measurement of nicotinamide adenine dinucleotide and related compounds by liquid chromatography/electrospray ionization tandem mass spectrometry, Anal Biochem, 352 (2006) 282-285.

[24] P. Belenky, F.G. Racette, K.L. Bogan, J.M. McClure, J.S. Smith, C. Brenner, Nicotinamide riboside promotes Sir2 silencing and extends lifespan via Nrk and Urh1/Pnp1/Meu1 pathways to NAD(+), Cell, 129 (2007) 473-484.

[25] R.M. Anderson, K.J. Bitterman, J.G. Wood, O. Medvedik, H. Cohen, S.S. Lin, J.K. Manchester, J.I. Gordon, D.A. Sinclair, Manipulation of a nuclear $\mathrm{NAD}(+)$ salvage pathway delays aging without altering steady-state NAD(+) levels, J Biol Chem, 277 (2002) 18881-18890.

[26] D.H. Williamson, P. Lund, H.A. Krebs, The redox state of free nicotinamide-adenine dinucleotide in the cytoplasm and mitochondria of rat liver, Biochemical Journal, 103 (1967) 514-527.

[27] M. Stubbs, R.L. Veech, H.A. Krebs, Control of the redox state of the nicotinamide-adenine dinucleotide couple in rat liver cytoplasm, Biochemical Journal, 126 (1972) 59-65.

[28] J.W.T. Wimpenny, A. Firth, Levels of Nicotinamide Adenine Dinucleotide and Reduced Nicotinamide Adenine Dinucleotide in Facultative Bacteria and the Effect of Oxygen, Journal of Bacteriology, 111 (1972) 24-32. 